\title{
Tourism vs. Environment: A Sociological Analysis
}

\author{
Mohammad Taghi Sheykhi \\ Alzahra University, Tehran, Iran
}

\begin{abstract}
The paper explores how the two concepts of tourism and environment affect each other. At present, tourism is known as an industry within the nations creating large amount of wealth, and thereby increasing GNP of different countries. Similarly, in post industrialization era, many citizens could have savings, and by the means of which could start traveling. Such travels were then improved and called tours. The result of tourism industry is transferring national resources from a country to another. Such an interaction creates prosperity in the destination target. Likewise, speed of transportation has widely contributed to boosting tourism. Distribution and dissipation of information on countries and regions have positively impacted tourism. Yet, tourism occasionally endangers the environment through the creation of roads, buildings etc. The paper discusses how tourism contributes to cultural development, economic prosperity, and cultural exchange between nations. Overall, tourism can create new environments. It is worth notifying that promotion of tourism yet depends on quality environment. Method of research used in the present article is of qualitative type. Conclusion asserts that industrialization improved tourism in different dimensions.
\end{abstract}

Keywords: tourism, industrialization, environment, cultural exchange, cultural development

\section{Introduction}

Development of tourism through preparing and construction of natural spaces which is attractive to tourists adds prosperity to industry, and in addition, it provides promotion to the environment. Tourism industry needs to put up with its necessary backgrounds in order to develop the industry. Infrastructures such as roads, means of communications, creations of natural resources, make ready seasides and resorts and like that are all essentials of tourist industry. Investment in such infrastructures which hold long-term perpetuation helps in increasing occupational resources, income generation, and increase in national wealth of countries. Tourist industry would also help in the promotion of the culture of environmental protection. Tourist industry is a new industry needing the least primary materials. Therefore, different countries except the Western European countries need to put its development on their agenda.

Development of tourism leads to good outcomes for the people living in those places. Development of the industry contributes to more benefits and prosperity for the residents of the destination place. For example, historical cities which are more in contact with more tourists are subject to more prosperity in terms of economic growth and cultural development. If the industry sustains, it will transfer increasing financial resources to the destination place. In the meantime, the appearance of city in terms of housing construction, protection of natural resources, safegrounding environment, and many more are prone to better position of tourist industry. So, tourist industry can positively be called in industry contributing to prosperity and

Mohammad Taghi Sheykhi, Professor Emeritus of Sociology, Alzahra University, Tehran, Iran. 
protecting the environment. However, tourism is travel for pleasure or business, also the theory and practice of touring, the business of attracting, accommodating, and entertaining tourists, and the business of operating tours (Tourism, 2005).

In the meanwhile, development of tourism has negative and hidden consequences too, which could be discussed. As the tourists always see the selves as guests and temporary in the destination sites, they may make use of abnormal patterns of behavior leading to deviance and social abnormalities. While balancing/comparing, so far as productivity is concerned, tourist industry has positive increasing dimensions; therefore the host sites generally do not pay any attention to the negative and destructive dimensions of the issue. It is worth mentioning that tourism occasionally endangers the environment; creation of roads, buildings, and the like, cause destructing the environment to a large extent. For example, the historical city of Agra in India, daily hosts over 4,000 tourists that increasingly hurt environmental noise, commuting pollutions, etc. Improved market of tourism contributes to the growth of awareness among the people in destination sites. It also brings a change in the lifestyle of people from agriculture (a survival level) to cash economy. Such a great change is highly welcomed and appreciated by the people of the host sites. Many people of the new lifestyle of cash economy involved in various businesses highly evade taxes and continue their businesses underground, with special reference to the developing countries.

\section{Method of Research}

Methodology used in the present research is of qualitative type which is increasingly popular in social sciences. In that, interview highly contributes in clarifying views. However, interview method was used in this research simply to discover something new. To conduct the research, the following techniques, tools, and procedures have been employed:

1. Books, documents, and other relevant sources of information.

2. Observation: The researcher used this method too through visiting people and centers concerned to delve tourism and environment issues.

3. Interview: Interviews were mainly used to find ideas, probe responses, and investigate feelings which questionnaires can never do. This flexible method was used as a means to understand the variables associated with tourism and environment.

Though this qualitative method in nature, ideas, attitudes, views, feelings behavior of the respondents were sought in order to assess the issues. It provided the author with the opportunity to observe things from very close quarters.

\section{Tourism vs. Social Sciences}

Anthropologists and other social scientists paid little attention to tourism before. Though tourism a product of industrial countries, yet social scientists have little investigated in that. However, sociologists of tourism and environment could create some literature, and have discussions and analyses on that in recent years. Consequently, new theorists of social sciences could reach positive conclusions on the issue, and thereby could improve it. They could reach out the results that tourism contributes to cultural development, economic prosperity, and cultural exchange between nations etc. As tourism happened at a small scale in the past, anthropologists and sociologists did not widely put it on their agenda. With the development of tourism, the economists highly paid attention to it. They then called it as a modern economy. That is, a type of economy that 
almost continues in a self-propelling manner. That is, through the revenues drawn from tourism functions, its extension on and infrastructures could be maintained. Many developing countries have recently followed suit with the developed countries to advertise and extend tourism in order to boost their economic growth and GNP.

Industrial nations that do not have high records from the developing nations have eagerly started visiting these countries. Though the action is one sided, yet it culminates in a good income for the developing nations such as Turkey, India, China, and many countries in Africa. Because of that many of the developing countries are currently planning and setting strategies to develop their tourist industry in order to generate more income and higher economic development.

Since 1995, the subject-matter of tourism has found a prime importance simply because of its economic dimension (Cohen, 1995). Lifestyles in non-Western countries are good attractions for the Western citizens from cultural, social, and natural viewpoints, and that plays a determining part in boosting tourism. Though tourism industry may have negative impact on natural resources, yet its economic benefits and concessions under-shadow the former in recent years a considerable portion of GDP of developing countries is dependent on tourist industry.

In terms of international trade, tourism played an unprecedented role in the past few years through the movement of above 425 million tourists, creating above 230 billion dollars which is a large circulation of money within nations (Smith \& Eadington, 1992). Therefore, development of tourism is followed by development of employment, more income generation, cultural development, modification and improvement of tourist resources etc. Thus, countries must follow the development of tourist industry after their industrialization, merely because it increases the national income as well as the per capita income.

Table 1

Ranking of Tourism in Selected Countries 2018

\begin{tabular}{llll}
\hline Rank & Country & UNWTO region & International tourist arrivals (2018) \\
\hline 1 & France & Europe & 89 million \\
2 & Spain & Europe & 83 million \\
3 & United States & North America & 80 million \\
4 & China & Asia & 63 million \\
5 & Italy & Europe & 62 million \\
6 & Turkey & Europe & 46 million \\
7 & Mexico & North America & 41 million \\
8 & Germany & Europe & 39 million \\
9 & Thailand & Asia & 38 million \\
10 & United Kingdom & Europe & 36 million
\end{tabular}

Source: “International Tourism Highlights”, UNWTO, 2019.

Since 1960, tourism has had an annual growth rate of 10\%; a growth that will continue in future too (The Economist, 1989). Growth of tourism in many cases caused the promotion environment. For example, many of the Mexican beaches were modified and modernized in recent years in order to attract more tourists, and thereby, to generate more income. Not only Mexico, but many other countries have gone the same way, and used the same policies. Tourism changes the interior industrial function, affects the social systems, because of that the local economies are influenced. Such procedures are followed in order to respond the foreign markets (Hall, 1994). Therefore, tourist industry in addition to its economic impacts has increasing social, cultural, and 
environment impacts as well; it changes many traditions. Tourism also changes large parts of local culture and gradually the values relevant to it.

Tourism can act as a source of foreign exchange. Such an action has played well for countries like Mexico, Turkey, etc. The income drawn from tourism can be used in industrial development, investment in economy, transportation sectors etc. Therefore, many countries have been dependent on tourism income since the later part of the 20th century, and based on that, they have grown their industrial and economic position. The above-mentioned development has highly improved the quality of life in those countries.

\section{Quality of the Environment and Tourism}

In countries like Mexico and Turkey, tourist industry being identified as an important source of foreign income, also known as a highly competitive industry, many of the managers of tourism companies are constantly searching for new destinations to use (Geshekter, 1978). As a new exploration, many of tourism company managers, while finding new tourism markets, created a mutual economic promotion. It means that on the one hand, the tourist companies earned large benefits, and on the other hand, the destination countries reached extensive and unprecedented income which was converted to sustained economic development in these countries. In the meanwhile, economic development in destination countries would enable the people of these countries to travel and tour to other countries. In this way some sort of cultural exchange would happen, and thereby the natural and unnatural environments would be reformed and modernized in order to attract more tourists. In such a way, tourist industry can create new environments.

Therefore, through such income the status of the poor in changed, new openings are established, improved discipline is created, and eventually more green spaces and safe environment are the results. Hence, income through tourism creates some of economic revolution the in host countries concerned. Similarly, while tourist industry tries to plan a safe and secure environment, expects of various kinds try to step in to bring about improvement in the industry concerned. Tourism in general and resort tourism in particular, employ some people from rural areas to cultivate the mineral springs on the sea resorts that are a help to employment (UN Projections, 2015). Therefore, it is the tourists who pay for the expenses of workers, the farmers, handcrafts men, etc. Circulation of money drawn from tourism is quite extensive and inclusive. However, through tourism various regions, forests and the like get better discipline and improved. Tourism development having different dimensions and impacts, mainly positive and seldom negative, contributes to environmental and economic development.

\section{Negative Aspects of Quality of Environment vs. Tourism}

Promotion of tourism depends on quality of environment. In fact quality environment is generally attractive to tourists. Nowadays, tourists of any type and class are highly sensitive to environmental conditions and pollution. Environmental conditions are responsible for declines in tourism. For example, insecurity and unhealthy environment in Britain due to radioactive activities caused the closure of many seasides, and in Haiti, increasing sewage pollution highly decreased tourism in that country. Similarly, many African countries, because of malayria and dangers of that kind, are having serious declines in the tourist industry. Therefore, creation of a safe environment or creation of a healthy space and public security, each plays an important role in tourism market. Pollution and environmental problem contributed to the closure of 600 villas on resorts in Mexico City. Likewise, how the industrial growth goes on and how the natural resources are exploited and activities like that, all affect the environmental security, have determining impacts on tourist industry. During 
the recent decades tourism to destinations within the polar sites has been identified and practiced; an adventure has never done before (Muller, Lundmark, \&Lemelin, 2013).

\section{Group Tourism}

Group tourism is practiced to a certain destination with the intention of leisure time spending. Overall, in the 20th century, and especially since the 1960s group tourism found a better market. This kind of tourism mainly started from North America to Caribbean reign and Africa. Today, it is practiced in other countries of the world too. Group tourism is criticized for the fact that it destroys the local culture (place of visit). Right after the beginning of group tourism, the UN World Environmental Organizations (WEO) was established to acknowledge governments of the challenges due to ecosystem, and somehow to protect the natural integration. During the 1950s and 1960s, the dominant paradigm emphasized on group tourism, and accepted any possible challenges versus obtaining wealth. Under such circumstances group tours from Germany to Thailand were under threats (Swanson, 1992). In the meantime, despite the threats, and the weaknesses, high priorities were given to group tours.

Despite the under-management of environment, tourism was highly advertised through pictures, brochures, etc. In this way group tourism was widely customized. In recent years many governments have actively promoted group tourism within the natural and protected areas (Johnas, 1992). However, group tourism despite its increasing income, has caused damages to the environment.

\section{Economic Value of Tourism}

Few studies have estimated/appraised the value of ecotourism within the protected areas. That is more because sufficient information has not been collected in the relevant arena through private sector, governments, and the UN World Environment Organization (WEO) in a scientific and systematic manner. The reason for that may be that it is a new area of tourism (Filion, Foley, \& Jacquemot, 1992).

Ecotourism includes visiting the far away area/spaces, rural areas, natural sites, and the like. Those are the places and areas for which large investment has not occurred. Ecotourism includes:

- Travel to natural destinations.

- It has the least impact.

- It increases awareness on natural space.

- It brings about benefits for the local people.

- It provides respect to local culture.

- Human rights support it, and it causes democratic movements.

\section{Conclusion}

Industrialization and appearance of new means of transportation have widely and highly affected tourist industry in the past two centuries. The more we enter the 21st century, the more increase we witness the development of tourism. Though it was primarily an industry being practiced by the wealthy industrial nations, it has gradually become a habit of developing nations too. Tourism is now mutually practiced among nations, though not in a balance and equally practiced. However, the stressful life of the current time has made travel and tourism very competitive. Tourism not only happened to cities, but villages and natural resources are on the agenda, and many tourists visit those places through group tours and upon their wishes and curiosity. Nowadays, most of the world tourism though belongs to the industrial world. Natural, social, and cultural 
parameters widely play as motivations to do so. Ecotourism also as a new form of tourist activity takes many people to virgin lands and resources not touched earlier. It is in an action with good income for the host place/country.

\section{References}

Cohen, E. (1984). The sociology of tourism: Approaches, issues, and findings. Annual Review of Sociology, 10, 378-379.

Filion, F. L., Foley, J. P., \& Jacquemot, A. J. (1992). The economics of global ecotourism. Unknown Publisher.

Geshekter, C. L. (1978). International tourism and national development: Some reflections on Kenya. In M. D. Zamora, V. H.

Sutlive, and N. Altshuler, Tourism and economic change (pp. 57-88). Williamsburg: Va. Dept of Anthropology.

Hall, C. M. (1994). Tourism and politics, policy, power and place. Chichester and New York: John Wiley.

Johansen Neil, C. (1992). Alaska: A developing state's strategies for establishing and developing parks and creating tourism facility operation cost recovery programs. Alaska: Manuscripts Collections.

Muller, D. K., Lundmark, L., \& Lemelin, R. H. (2013). New issues in polar tourism. Dordrecht: Springer.

Sheykhi, M. T. (2017). Environmental sociology. Tehran: Harir Publication.

Smith, V. L., \& Eadington, W. R. (1992). Tourism, alternatives, potentials and problems in the development of tourism. Philadelphia: University of Pennsylvania Press.

Swanson, M. A. (1992). Ecotourism: Embracing the new environmental paradigm. London: UK Publications.

Third-world tourism. (March 11, 1989). The Economist, p. 19.

Tourism. (2005). Oxford English dictionary. Oxford: Oxford University Press.

UN Projections for 2015. (2015). The population pressures in Mexico are rural enough. Metropolitan Mexico City will have a population of 18.7 million.

UNWTO. (2019). International tourism highlights. 